\title{
A EDUCAÇÃO E A COMUNICAÇÃO AMBIENTAL TRANSFORMADORA: ABORDAGENS, DIRETRIZES E PRÁTICAS NA GESTÃO DE BACIAS HIDROGRÁFICAS
}

\author{
Vinicius Perez Dictoro ${ }^{1}$ \\ Frederico Yuri Hanai ${ }^{2}$
}

Resumo: A distância temporal dos problemas ambientais, aliada aos efeitos abstratos em um primeiro momento dos impactos ambientais que não afetam diretamente as pessoas, provoca dificuldades para o despertar de uma consciência ecológica e um comportamento pró-ambiental. Para isso, os campos de estudo da Educação Ambiental e da comunicação ambiental poderão auxiliar as pessoas no sentido de despertar para novos comportamentos e compreensões do mundo. Assim, o objetivo desse artigo é identificar e contribuir com práticas, diretrizes e ações que envolvem a educação e a comunicação ambiental em bacias hidrográficas, sob a ótica e opiniões de integrantes da Câmara Técnica de Educação Ambiental do Tietê Jacaré (CTEA-TJ).

Palavras-chave: Educação Ambiental; Comunicação Ambiental; Bacias Hidrográficas; Diretrizes de Ações.

Abstract: The temporal distance from environmental problems, combined with abstract effects in the first instance of environmental impacts that do not directly affect people, causes difficulties in awakening an ecological awareness and pro-environmental behavior. For this, the fields of study of environmental education and environmental communication can help people to awaken to new behaviors and understandings of the world. Thus, the objective of this article is to identify and contribute to practices, guidelines and actions that involve environmental education and communication in hydrographic basins, under the optics and opinions of members of the Technical Chamber of Environmental Education of Tietê - Jacaré (TCEE-TJ).

Keywords: Environmental Education; Environmental Communication; Watersheds; Action Guidelines.

\footnotetext{
${ }^{1}$ Doutor em Ciências Ambientais. E-mail: vinicius.dictoro@gmail.com, Link para o Lattes: http://lattes.cnpq.br/9469471717661914

2 Universidade Federal de São Carlos. E-mail: fredyuri@ufscar.br, Link para o Lattes: http://lattes.cnpq.br/7651828454575175
} 


\section{Introdução}

As bacias hidrográficas proporcionam uma relação entre os estudos nas áreas de ciências naturais e humanidades, além de outras áreas do saber científico, permitindo uma discussão das questões sociais e ambientais (PINTO; BORGES, 2015). Considera-se que as bacias hidrográficas são os espaços ideais para a gestão de recursos hídricos, possibilitando interações nas dimensões sociais, econômicas, ambientais e até mesmo culturais. Nesse sentido, Vilaça et al. (2009) reforçam que a bacia hidrográfica pode ser considerada uma excelente unidade de gestão, tanto de elementos naturais, quanto sociais, devido à possibilidade de integração entre sociedade e meio ambiente.

Tundisi (2013) ressalta as principais características que reforçam a importância das bacias hidrográficas como unidade de planejamento e gestão:

- A bacia hidrográfica é uma unidade física com fronteiras delimitadas, facilitando a questão do planejamento dessas áreas;

- É um ecossistema hidrologicamente integrado que engloba aspectos sociais, econômicos, culturais e ambientais;

- Oferece oportunidades para o desenvolvimento de parcerias e a resolução de conflitos;

- A utilização da bacia hidrográfica como unidade de planejamento e gestão irá permitir que a população local participe do processo de decisão;

- Pode promover a integração institucional para o gerenciamento do desenvolvimento sustentável, permitindo associações entre o poder público, instituições de ensino e pesquisa, além da sociedade civil para buscar melhores soluções e alternativas para a bacia hidrográfica.

As bacias hidrográficas são espaços que se caracterizam pela integração de fatores físicos influenciados diretamente pela ocupação e ação humana, ou seja, as bacias hidrográficas são, portanto, o palco de processos naturais e, ao mesmo tempo, sofrem modificações pelas atividades humanas (BACCI; PATACA, 2008). Devido a esses aspectos, as bacias hidrográficas podem ser consideradas referências para análise dos problemas socioambientais e para a pesquisa, atividades e ações de Educação Ambiental e comunicação ambiental (OLIVEIRA, 2002).

Os problemas socioambientais requerem soluções pautadas na colaboração e na cooperação mútua das pessoas responsáveis pela tomada de decisão na gestão de bacias hidrográficas e da sociedade em geral, pois a grande maioria dos problemas socioambientais são decorrentes da ação 
humana no meio ambiente. Ainda assim, é difícil visualizar na prática todos os problemas que a sociedade vem causando na natureza, pois os principais atingidos pela situação que se vive no mundo de hoje são as populações mais vulneráveis. As alterações impostas pelos seres humanos estão modificando os ciclos naturais do planeta cada vez mais, intensificando situações extremas e ocasionando maiores impactos socioambientais que podem afetar a sociedade em geral.

A distância temporal dos problemas ambientais, aliada aos efeitos abstratos em um primeiro momento dos impactos ambientais que não afetam diretamente as pessoas, provoca dificuldades para o despertar de uma consciência ecológica e um comportamento pró-ambiental. Para isso, os campos de estudo da Educação Ambiental e da comunicação ambiental poderão auxiliar as pessoas no sentido de despertar para novos comportamentos e compreensões do mundo.

O meio ambiente e os elementos naturais são essenciais à vida, e estão sempre presentes na pauta das discussões sobre o desenvolvimento. Assim, é importante a busca por alterar e melhorar a percepção e compreensão sobre os elementos naturais. Para isso, as ações práticas, reflexivas e teóricas de Educação Ambiental e da comunicação ambiental poderão ajudar a entender e compreender os elementos naturais e o meio ambiente como aspectos integrados da própria vida humana, e não apenas como um bem a ser consumido e utilizado pelos seres humanos (TEIXEIRA, 2007), características que estão relacionadas a uma abordagem transformadora da Educação Ambiental e da comunicação ambiental. Loureiro (2004) destaca que a adjetivação "transformadora" tem como base estimular o diálogo democrático para promover 0 questionamento às abordagens comportamentais no entendimento das relações culturais da sociedade com a natureza, revolucionando os indivíduos em suas subjetividades e práticas nas estruturas sociais-naturais existentes.

Os conceitos da educação e comunicação ambiental transformadora enfatizam a transformação da realidade de vida, buscando redefinir o modo como a sociedade se relaciona com ela mesma, com as demais espécies e com o planeta. Por isso, trata-se de processos de politização da problemática socioambiental, buscando romper com práticas sociais contrárias ao bem-estar público, à equidade e à solidariedade (LOUREIRO, 2004).

A comunicação ambiental é um campo de atuação que abrange diferentes formas e contextos de comunicação sobre as questões socioambientais, ou seja, é uma ferramenta importante para a ação ambiental, podendo interferir diretamente no potencial transformador das interações educativas. Para que a comunicação ambiental possa proporcionar aprendizado e gerar transformação é fundamental que seu conteúdo seja cuidadoso, adequado e compreenda as três dimensões da Educação Ambiental: participação, valores e conhecimentos. 
O objetivo deste artigo é identificar e contribuir com práticas, diretrizes e ações que envolvem a educação e a comunicação ambiental em bacias hidrográficas, sob a ótica e opiniões de integrantes da Câmara Técnica de Educação Ambiental do Tietê - Jacaré (CTEA-TJ).

\section{Procedimentos metodológicos}

Sob o ponto de vista da natureza metodológica deste artigo, este trabalho tem caráter de pesquisa aplicada. Conforme Gil (2002), a pesquisa aplicada possui como característica fundamental o interesse na aplicação, utilização e consequências práticas das informações levantadas. Barros e Lehfeld (2000, p. 78) reforçam que a pesquisa aplicada tem como motivação a necessidade de produzir conhecimento para aplicação de seus resultados, no intuito de: "contribuir para fins práticos, visando à solução mais ou menos imediata do problema encontrado na realidade".

Para este estudo, foram utilizados dois métodos para a obtenção de informações e dados que podem contribuir com práticas, diretrizes e ações envolvendo a educação e a comunicação ambiental em bacias hidrográficas. Inicialmente, seguiu-se com o levantamento bibliográfico por meio da pesquisa em artigos científicos, periódicos e teses que abordam essa temática, e, em seguida, foi realizada a análise desses materiais.

Já para a segunda parte deste artigo, foi efetuada uma pesquisa participativa com membros da Câmara Técnica de Educação Ambiental do Comitê de Bacia Hidrográfica do Tietê - Jacaré (CTEA - TJ) e especialistas em Educação Ambiental, pessoas que estão diretamente envolvidas com a gestão de bacias hidrográficas. O objetivo desta etapa foi obter as opiniões dessas pessoas sobre possíveis melhorias que devem ser realizadas para uma efetiva gestão de bacias hidrográficas e melhorias nas ações de Educação Ambiental. Para isso, a seguinte questão foi proposta como instrumento de pesquisa: "Na sua opinião o que pode e/ou deve ser melhorado na gestão de bacias hidrográficas e na Educação Ambiental? Essa questão foi enviada por meio de um formulário online para os participantes do estudo.

\section{Sujeitos da pesquisa}

Os comitês de bacias hidrográficas desempenham um papel fundamental dentro da Política Nacional de Recursos Hídricos, com atribuições normativas, deliberativas e consultivas a serem exercidas nas bacias hidrográficas (CARDOSO, 2003; ABERS; JORGE, 2005). Devido a esse fato, os membros dos $\mathrm{CBHs}$ possuem grande importância no contexto da estrutura e gestão dos recursos hídricos, assim como conhecimentos, experiências e práticas sobre a gestão da água, por isso a opinião dessas pessoas é relevante e essencial para esse estudo. 
No âmbito das bacias hidrográficas, os membros dos CBHs são considerados os principais agentes de comunicação, pois estão diretamente relacionados com a gestão e conservação da água em bacias hidrográficas, sendo responsáveis pela aprovação dos Planos de Recursos Hídricos, podendo arbitrar sobre os possíveis conflitos pelo uso da água, além de estabelecer mecanismos, atividades e ações que poderão ser realizadas.

Em vista disso, foi feito o convite para a participação dos membros da Câmara Técnica de Educação Ambiental do Comitê de Bacia Hidrográfica do Tietê - Jacaré (CTEA - TJ) e de especialistas de Educação Ambiental, pois estão diretamente relacionados com a gestão de bacias hidrográficas e na atuação de atividades e práticas de Educação Ambiental que visam contribuir para uma melhor gestão e conservação da água.

O Quadro 1, a seguir, apresenta uma caracterização geral do perfil dos 16 participantes desta pesquisa:

Quadro 1: Perfil dos respondentes da pesquisa.

\begin{tabular}{|c|c|c|c|}
\hline \multirow{2}{*}{ Aspectos } & Respostas & Números & $\begin{array}{c}\text { \% (valores } \\
\text { aproximados) }\end{array}$ \\
\hline \multirow{2}{*}{ Gênero } & Feminino & 11 & 69 \\
\cline { 2 - 4 } & Masculino & 5 & 31 \\
\hline \multirow{3}{*}{$\begin{array}{c}\text { Formação } \\
\text { relacionadas } \\
\text { às áreas }\end{array}$} & Educação & 5 & 31 \\
\cline { 2 - 4 } & Engenharia & 5 & 31 \\
\cline { 2 - 4 } & Biologia & 4 & 26 \\
\hline \multirow{3}{*}{\begin{tabular}{c} 
Representação \\
\cline { 2 - 4 }
\end{tabular}} & Agronomia & 1 & 6 \\
\cline { 2 - 4 } & Estado & 1 & 6 \\
\cline { 2 - 4 } & Município & 4 & 6 \\
\hline
\end{tabular}

Fonte: Elaboração dos autores (2021).

Nota-se que a maioria dos participantes desta pesquisa são representantes do gênero feminino (69\%), destacando o envolvimento e a importância das mulheres nas atividades e ações de Educação Ambiental. Pode-se observar também, que os participantes possuem uma formação relacionada com as áreas da educação, engenharia e ambiental (biologia, geografia e agronomia). Representam na sua maioria o setor de usuários da água e sociedade civil organizada, além de representantes dos municípios e do Estado.

Vale reforçar que dentro do Estado de São Paulo, os usuários da água fazem parte do grupo de representantes da sociedade civil organizada, diferentemente do que ocorre em grande parte dos outros estados brasileiros (BARBOSA, 2019), por isso ocorre um maior número de representantes nesse setor.

Revbea, São Paulo, V. 16, № 6: 104-124, 2021. 


\section{Diretrizes e abordagens envolvendo a Educação Ambiental, comunicação ambiental e gestão de bacias hidrográficas}

A pesquisa obteve a participação de 16 respondentes cujos depoimentos foram classificados e identificados em categorias de análise, com base nas suas respectivas respostas. As categorias de análise identificadas foram as seguintes:

- Informação e divulgação das ações e atividades de Educação Ambiental para a população;

- Valorização da cultura local e respeito com a natureza pelas pessoas;

- Envolvimento e participação da população nas ações e atividades de Educação Ambiental;

- Continuidade das ações e atividades de Educação Ambiental;

- Gestão integrada.

Na primeira categoria de análise, informação e divulgação das ações e atividades de Educação Ambiental para a população, destacam-se depoimentos que ressaltam a importância de divulgar os estudos realizados, trazer uma linguagem adequada para que toda a população possa conhecer e saber das ações que vêm sendo realizadas, além da importância da Educação Ambiental presente no cotidiano das pessoas. A seguir apresentam-se os três depoimentos referentes à essa categoria de análise:

"Um ponto que poderia ser mais trabalhado era na questão de levar esses dados para a população, mostrar a importância desses estudos, da percepção dos moradores e de como os recursos ali são importantes. Vejo essa pesquisa com um potencial muito grande em trazer dados consistentes e que consiga expor isso para "pessoas comuns" e comunidade científica, incentivando que ambas as partes trabalhem em harmonia e união, fortalecendo a Educação Ambiental e trazendo mais sentido para gestão de bacias, de não ficar algo preso a poucas pessoas" (Respondente 1).

"Creio que a integração de informações é algo importante e que nem sempre ocorre nas gestões em diversos campos. Os problemas/dificuldades não ocorrem sozinhos e tampouco são solucionados sozinhos. É extremamente importante que haja uma visão sistêmica para resolução conjunta dos problemas. A Educação Ambiental precisa ser parte do cotidiano das pessoas. Por isso que estudos como este devem ser cada vez mais recorrentes, para que a educação e sensibilização ambiental esteja presente de diversas formas, no nosso dia-adia" (Respondente 5). 
"Disponibilização de maiores informações, transmissão de conhecimentos, despertar o sentido de pertencimento da população local na bacia hidrográfica" (Respondente 7).

Nos três depoimentos, categorizados na primeira categoria de análise, destacam-se a informação e transmissão do conhecimento para todas as pessoas presentes nas bacias hidrográficas. As informações não devem ser limitadas aos aspectos científicos e técnicos, devem ser claras e informar toda a população. Com isso, pode surgir um maior comprometimento e relação das pessoas com a questão ambiental, verificando o que de fato vem acontecendo naquele local e as principais causas e desafios para possíveis soluções dos problemas socioambientais.

Já a categoria de valorização da cultura local e respeito com a natureza pelas pessoas aborda a questão da importância da consideração de todos os seres vivos na bacia hidrográfica, valores de respeito à natureza, além da promoção do contato com o meio ambiente. A seguir apresentam-se os depoimentos que foram enquadrados nesta categoria de análise:

"Consideração de todos os seres vivos presentes na bacia hidrográfica, valores que são trabalhados na Educação Ambiental. Valorização da cultura local, diversidade cultural e social, além da consideração e respeito das pessoas com a natureza" (Respondente 2).

"A Educação Ambiental deveria ser mais explorada entre associações de bairro, moradores locais e projetos existentes pelas prefeituras. Algumas localidades possuem uma associação forte e estruturada e realizam ações em parques e praças públicas, porém ainda é muito pouco perto do potencial que se tem para organizar novos projetos, novas interações e promover o contato com o meio ambiente" (Respondente 11).

"Incentivar a cultura local, atividades ao ar livre e na natureza, mostrar a importância cultural de algumas áreas da cidade, mostrar a importância ambiental dos rios urbanos" (Respondente 16).

Observa-se nos depoimentos presentes na categoria de valorização da cultura local e respeito com a natureza, a importância de realizar uma Educação Ambiental com abordagem emancipatória, transformadora e crítica, devido ao fato de possuir as características citadas pelos participantes da pesquisa, como: valorização da cultura local; interações e contato com o meio ambiente por meio de atividades e ações; ressaltar a importância ambiental e cultural dos lugares. Dessa forma, busca-se provocar mudanças e atitudes nos 
comportamentos individuais e coletivos das pessoas promovendo o contato e a interação com o meio ambiente.

Outra categoria identificada foi a de envolvimento e participação da população nas ações e atividades de Educação Ambiental, na qual os respondentes citaram a necessidade de um maior envolvimento e participação da população nas atividades e ações de Educação Ambiental e gestão de bacias hidrográficas. Apresentam-se a seguir os quatro depoimentos presentes nesta categoria:

"Maior incentivo de prefeituras e governos nas ações de Educação Ambiental para escolas, ONGs, instituições, e também um maior envolvimento e participação da população local nesses meios" (Respondente 3).

"Acredito que um dos principais pontos em comum do que deve ser melhorado na gestão das bacias hidrográficas, que é influenciado pela Educação Ambiental, é a divulgação da importância da sua existência, bem como sensibilização que está só se dá de forma justa através da participação e integração" (Respondente 4).

"Participação pública efetiva e ativa, atividades que gerem pertencimento" (Respondente 6).

"Aumento da participação da população local e da comunidade nas ações de Educação Ambiental em bacias hidrográficas. Informações disponibilizadas com linguagem simples e adequada para todas as pessoas" (Respondente 9).

Nesse caso, os quatro depoimentos dos respondentes estão alinhados com as principais características de uma Educação Ambiental com abordagem emancipatória, crítica ou transformadora e ainda com a abordagem transformadora da comunicação ambiental, que incentivam e ressaltam a importância da participação pública nas ações e atividades que serão planejadas e/ou executadas nas bacias hidrográficas.

Outro aspecto de grande importância citado pelos respondentes, referese à categoria de continuidade das ações e atividades de Educação Ambiental. Percebe-se que muitas vezes as ações e atividades realizadas de Educação Ambiental são feitas de maneira pontual em datas comemorativas ou realizadas apenas uma vez e esquecida em outros anos. Os depoimentos a seguir representam essa categoria de análise: 
"Acredito que o que deve ser melhorado é a continuidade das ações, práticas e projetos ao longo do tempo. E nesse sentido também, a realização de estratégias para que as pessoas de alguma forma continuem engajadas e motivadas para contribuir com essa continuidade em um âmbito primeiro mais pessoal, podendo ampliar para o coletivo" (Respondente 8).

"Na minha opinião um dos grandes problemas relacionados à Educação Ambiental decorre da falta de continuidade das ações e atividades que são realizadas, existe essa carência de continuar as atividades desenvolvidas e não realizar apenas ações pontuais em determinadas datas comemorativas ou épocas do ano" (Respondente 13).

A descontinuidade nas ações e atividades de Educação Ambiental é fato que acontece frequentemente. Muitas vezes, os projetos de Educação Ambiental realizam atividades pontuais que após a finalização do projeto acabam sendo esquecidas e não são mais retomadas. A abordagem emancipatória, transformadora e crítica da Educação Ambiental almeja promover ações e atividades que integrem a sociedade com a natureza, visando comportamentos e atitudes benéficas ao meio ambiente que devem ser transmitidas ao longo das gerações, ou seja, realizando ações de mudanças comportamentais duradouras de forma a proteger e preservar o meio ambiente. Além disso, essa abordagem pretende despertar o desejo de cuidado e pertencimento àquele lugar, fazendo com que as ações e atividades programadas não sejam apenas pontuais e perpassem para quando o projeto tiver sido finalizado.

A última categoria identificada está relacionada com a gestão integrada da água, que visa um modelo de gestão planejado que considere não só os múltiplos usos da água (industrial, abastecimento público, saneamento, drenagem, ambiental e ecossistêmico), mas também reforcem a necessidade da participação e mobilização da sociedade, que pode ser alavancada por meio da comunicação e da Educação Ambiental.

O depoimento a seguir representa essa categoria de análise:

"A Educação Ambiental deve ser mais ativa, propor mais práticas e atividades nas escolas, nos parques e em lugares onde se podem realizar essas ações. A gestão de bacias hidrográficas precisa ser pensada de maneira integrada, considerando os aspectos sociais, ambientais e econômicos, se não a degradação será sempre maior e a qualidade dos rios cada vez menor" (Respondente 14). 
uma efetiva gestão de bacias hidrográficas. Os dois depoimentos a seguir envolvem as categorias de informação/divulgação e envolvimento/participação:

"Maior auxílio aos projetos e atividades de Educação Ambiental; maior conhecimento e participação da população nestas atividades; maior divulgação dessas ações; engajar mais pessoas na luta por um meio ambiente equilibrado; planejamento adequado das ações e atividades propostas, e que esse planejamento seja aderente às necessidades $e$ desejos da população local" (Respondente 10).

"Maior informação para a população pode contribuir para uma maior participação das pessoas nas atividades de Educação Ambiental, se as pessoas ficarem sabendo e obtiverem informações de qualidade a procura por participação pode ser maior" (Respondente 15).

Os relatos mostrados nesta categoria englobam aspectos fundamentais da abordagem considerada a mais adequada para se trabalhar com a Educação Ambiental e comunicação ambiental em bacias hidrográficas, ou seja, a abordagem emancipatória, transformadora e crítica, pois ressaltam a importância da participação e da informação para todas as pessoas. Essas duas características são essenciais para que possa ocorrer um maior envolvimento das pessoas nas ações e atividades de Educação Ambiental nas bacias hidrográficas, possibilitando uma gestão eficiente e que de fato seja benéfica para a conservação do local, além de respeitada e integrada com as ações da população local.

Nesse outro depoimento estão presentes as categorias de envolvimento/participação e valorização da cultura local:

"A comunicação, o estímulo e motivação à participação, a valorização de diferentes culturas e melhores indicadores de monitoramento e avaliação são, para mim, alguns pontos a serem melhorados na gestão de bacias hidrográficas e na Educação Ambiental" (Respondente 12).

Aqui, o respondente aborda sobre uma comunicação adequada e um maior envolvimento da população nas ações realizadas, e ainda destaca a importância de realizar um monitoramento e avaliação dessas ações. 0 monitoramento e avaliação das ações e atividades são fundamentais para verificar se as ações planejadas estão de fato contribuindo para gerar comportamentos pró-ambientais e melhorar a gestão da água nas bacias hidrográficas. Para isso, as atividades devem estar relacionadas com as abordagens mais adequadas para se trabalhar em bacias hidrográficas. 
A partir dos depoimentos dos especialistas em Educação Ambiental e dos membros da CTEA - TJ, além do levantamento em referências bibliográficas nas áreas de Educação Ambiental e comunicação ambiental, foi possível elencar algumas diretrizes e possibilidades de ações que representam as opiniões e refletem sobre as experiências e alternativas a fim de contribuir para novas abordagens na educação e comunicação ambiental em bacias hidrográficas (Quadro 2).

Quadro 2: Diretrizes de ações para as atividades de educação e comunicação ambientais.

\begin{tabular}{|c|c|c|}
\hline Diretriz de ação & Principais pontos & Referências \\
\hline $\begin{array}{l}\text { 1) Linguagem } \\
\text { simples e adequada }\end{array}$ & $\begin{array}{c}\text { Ações e atividades compreendidas; maior } \\
\text { alcance dos conhecimentos e informações; troca } \\
\text { entre saberes técnicos, científicos, populares e } \\
\text { locais. }\end{array}$ & Ferreira et al. (2017). \\
\hline $\begin{array}{l}\text { 2) Mobilização e } \\
\text { envolvimento da } \\
\text { sociedade }\end{array}$ & $\begin{array}{l}\text { Identificar temas relevantes e locais; aumentar o } \\
\text { conhecimento das questões socioambientais; } \\
\text { respeitar a cultura local; mobilizar e envolver a } \\
\text { população. }\end{array}$ & $\begin{array}{c}\text { Perkins (2011); } \\
\text { Cohen; Saenz } \\
\text { (2017); Gao et al. } \\
\text { (2018); Barbosa } \\
\text { (2019). }\end{array}$ \\
\hline $\begin{array}{l}\text { 3) Ampliar a visão } \\
\text { da relação ser } \\
\text { humano e natureza }\end{array}$ & $\begin{array}{c}\text { Construção de novas perspectivas; interação } \\
\text { seres humanos e natureza; ampliar visão ser } \\
\text { humano e natureza. }\end{array}$ & $\begin{array}{l}\text { Dictoro \& Hanai } \\
\text { (2017); Dictoro et al. } \\
\text { (2019). }\end{array}$ \\
\hline $\begin{array}{l}\text { 4) Ressaltar valores } \\
\text { simbólicos, } \\
\text { culturais, } \\
\text { sentimentais e } \\
\text { tradicionais }\end{array}$ & $\begin{array}{l}\text { Novas maneiras de olhar para o meio ambiente; } \\
\text { novas maneiras de sensibilização. }\end{array}$ & $\begin{array}{l}\text { Martínez Gil (2007); } \\
\text { Dictoro \& Hanai } \\
\quad \text { (2017). }\end{array}$ \\
\hline $\begin{array}{l}\text { 5) Utilização de } \\
\text { imagens } \\
\text { provocativas e de } \\
\text { boa qualidade } \\
\text { visual }\end{array}$ & $\begin{array}{l}\text { Estimular a curiosidade; transmitir e explorar as } \\
\text { informações; criar conexões emocionais; } \\
\text { representar conteúdos locais. }\end{array}$ & $\begin{array}{l}\text { Schultz et al. (2018); } \\
\text { Godfrey \& Feng } \\
\text { (2017) }\end{array}$ \\
\hline $\begin{array}{l}\text { 6) Experiências de } \\
\text { contato com a } \\
\text { natureza e } \\
\text { aprendizagem na } \\
\text { natureza }\end{array}$ & $\begin{array}{l}\text { Contribuir para o aprendizado; aprender ao ar } \\
\quad \text { livre; sentimento de pertencimento; } \\
\text { aprofundamento e envolvimento das pessoas. }\end{array}$ & $\begin{array}{l}\text { Gérin-Lajoie et al. } \\
\text { (2018); Golob } \\
\text { (2011). }\end{array}$ \\
\hline $\begin{array}{l}\text { 7) Retratar } \\
\text { problemas locais e } \\
\text { ressaltar a cultura } \\
\text { local }\end{array}$ & $\begin{array}{c}\text { Compreender e retratar a realidade local; } \\
\text { sentimento de pertencimento e desejo de } \\
\text { cuidado; busca por um comportamento pró- } \\
\text { ambiental. }\end{array}$ & $\begin{array}{l}\text { HSU et al. (2018); } \\
\text { Gao et al. (2018). }\end{array}$ \\
\hline $\begin{array}{l}\text { 8) Estimular e } \\
\text { desenvolver } 0 \\
\text { aspecto coletivo }\end{array}$ & $\begin{array}{l}\text { Pensar coletivo e o ato de compartilhar; melhor } \\
\text { convivência e bem-estar social; comunidade } \\
\text { unida e democrática. }\end{array}$ & $\begin{array}{l}\text { Darwish \& Huber } \\
\text { (2003). }\end{array}$ \\
\hline $\begin{array}{l}\text { 9) Desenvolver e } \\
\text { criar conexões } \\
\text { emocionais e gerar } \\
\text { comportamentos } \\
\text { pró-ambientais }\end{array}$ & $\begin{array}{l}\text { Promover escolhas sustentáveis; gerar } \\
\text { comportamentos pró-ambientais; incorporar os } \\
\text { diversos tipos de conhecimento; retratar } \\
\text { problemas locais; despertar novos sentidos. }\end{array}$ & Liang et al. (2018). \\
\hline
\end{tabular}

Fonte: Elaboração dos autores (2021). 
A seguir apresentam-se as principais características das nove diretrizes de ações para as atividades de Educação Ambiental e de comunicação ambiental em bacias hidrográficas.

\section{Diretriz de ação 1 - Linguagem simples e adequada}

Uma das críticas encontradas na gestão de bacias hidrográficas vem do fato da pouca participação da sociedade nos espaços deliberativos que existem. A simples previsão legal desses espaços, por si só, não garante a participação da sociedade e nem a concretude de uma boa gestão da água. Muitas vezes, as pessoas se sentem inibidas de participar, por desconhecer a linguagem técnica e científica utilizada nestas instâncias de gestão. Para isso, deve-se facilitar 0 acesso à informação com uma linguagem simples e adequada para todas as pessoas, possibilitando a participação das comunidades nos processos e nas atividades relacionadas à gestão de bacias hidrográficas (FERREIRA et al., 2017).

A utilização de uma linguagem simples e adequada é fundamental para que as ações e atividades de Educação Ambiental sejam vistas e compreendidas por toda a sociedade. Dessa forma, poderá haver maior alcance dos conhecimentos e informações retratados em ações, estudos e atividades propostas, ou seja, não haverá limitação do conhecimento e/ou das atividades para apenas uma pequena parcela da sociedade.

Assim, torna-se possível ocorrer uma maior troca entre saberes técnicos, científicos, populares e locais, almejando expandir o diálogo e abrir caminho para novas visões e possibilidades que poderão ampliar a consciência socioambiental das pessoas. Além de uma linguagem simples e adequada, também é preciso entender o contexto de cada local em que a atividade ou ação será realizada, conversar e refletir sobre as necessidades daquela comunidade, bem como estar presente na escuta ativa e na possibilidade de mudanças, e, ainda, expor o que se pretende fazer e verificar a real necessidade de ação junto aos moradores locais.

\section{Diretriz de ação 2 - Mobilização e envolvimento da sociedade}

Segundo Barbosa (2019) e Perkins (2011), para o exercício de uma gestão efetiva da água e dos recursos hídricos, é imprescindível ampliar a participação da sociedade civil organizada e a participação social das pessoas nas decisões e processos na gestão de bacias hidrográficas.

Para isso, almeja-se uma maior mobilização e envolvimento das pessoas nas atividades e ações relacionadas à Educação Ambiental em bacias hidrográficas. Algumas iniciativas podem gerar resultados positivos nesse sentido e, assim, melhorar a compreensão dos principais problemas ambientais e criar uma abordagem de intervenção construtiva para auxiliar na relação com o meio ambiente.

revista brasileira educação ambiental 
As iniciativas de Educação Ambiental em bacias hidrográficas podem aumentar o conhecimento das questões socioambientais presentes nesse meio, criando um maior envolvimento da sociedade nestas ações e atividades (PERKINS, 2011). De acordo com Cohen e Saenz (2017), na medida em que as pessoas têm uma maior consciência dos problemas socioambientais presentes no meio ambiente local, estarão mais dispostas a participar de ações pró-ambientais, aumentando o envolvimento e a participação da sociedade nas atividades e ações planejadas. O estudo realizado por Junior et al. (2015) demonstrou que nas bacias hidrográficas em que a participação e o envolvimento da comunidade em ações foram maiores, os resultados obtidos nos índices de qualidade da água foram melhores. Reforça-se, assim, a importância de envolver a comunidade como parte integrante dos processos e atividades.

Algumas iniciativas que devem ser destacadas: identificar temas relevantes e locais; aumentar o conhecimento das questões socioambientais locais nas bacias hidrográficas; fornecer informações com linguagem simples e adequada; espaço aberto para opiniões e discussões; ambiente harmônico e diversificado; respeitar a cultura local.

À medida em que as pessoas conhecerem mais e se identificarem com o tema abordado, espera-se que estejam mais dispostas e propensas a participarem de ações pró-ambientais, além de ganharem mais conhecimentos e atitudes para propor soluções e melhorias para a realidade local.

Segundo Gao et al. (2018), recomenda-se que os gestores de recursos hídricos incentivem atividades comunitárias e o envolvimento público das pessoas locais nas bacias hidrográficas, criando elos de contato e de cuidado, além de também realizar uma comunicação ambiental nesses locais, como boletins informativos para as pessoas das comunidades.

\section{Diretriz de ação 3 - Ampliar a visão da relação ser humano e natureza}

A compreensão da relação ser humano e natureza precisa ser expandida, buscando novas perspectivas e resgatando relações antigas que superam as atuais formas utilitaristas desta relação. Deve-se propiciar uma construção conjunta e reflexiva sobre a interação dos seres humanos com o meio, com as plantas e animais, além de uma autorreflexão sobre si próprio e sua forma de se relacionar no mundo e com o mundo. Esses aspectos são discutidos e propostos em várias vertentes da Educação Ambiental (DICTORO et al., 2019).

Atualmente, se fazem necessárias as intervenções humanas na natureza a fim de sustentar os sistemas produtivos dos seres humanos e atender ao bem-estar social. Contudo, o principal problema está na forma exagerada de utilização e consumo da natureza e de seus elementos, ou seja, é preciso buscar um equilíbrio nesta relação. Por isso, deve-se pensar que 
existe um limite para tudo e adequar as ações com as realidades locais, sociais e ambientais.

Busca-se a construção de novas perspectivas, que transformem as formas de relação com a natureza dos dias de hoje. Para isso, deve-se construir uma relação conjunta de interação dos seres humanos com o meio ambiente, ressaltando valores simbólicos, culturais e sentimentais. Segundo Dictoro e Hanai (2017), é necessário valorizar todas as formas de relações com a natureza, a fim de reconquistar o sentido de pertencimento à natureza e respeito pelas diferentes culturas e modos de vida.

Almeja-se considerar a ideia de que a humanidade e a natureza são partes integradas e não devem ser pensadas apenas a partir de uma abordagem utilitarista. É preciso ampliar a visão da relação ser humano e natureza, resgatando aspectos simbólicos, sentimentais, tradicionais e culturais, a fim de integrar e construir outros tipos de sociedades, sustentadas sobre uma convivência harmoniosa entre seres humanos e natureza.

\section{Diretriz de ação 4 - Ressaltar valores simbólicos, culturais, sentimentais e tradicionais}

Sugere-se ampliar os meios de reflexão, discussão e conhecimentos para novas formas e abordagens de pensamento sobre as relações humanas com a natureza, ressaltando valores simbólicos, culturais, sentimentais e tradicionais. Englobar novas maneiras de olhar para o meio ambiente, levando em consideração conhecimentos, saberes e relações fundamentais para uma melhor Educação Ambiental e gestão de bacias hidrográficas.

Pode-se pensar em novas maneiras de se relacionar com a natureza e seus elementos naturais. No caso da água, nota-se que existem diversas relações que foram esquecidas ao longo dos anos, mas que ainda se encontram em comunidades tradicionais, ribeirinhas, indígenas e outras populações. Essas relações são pautadas em valores simbólicos, culturais, sentimentais e místicos.

Os aspectos simbólicos e culturais devem ser transmitidos em novas maneiras de sensibilização para a conservação da água. A sensibilização para conservação da água (englobando valores culturais, simbólicos, místicos e afetivos), aliada às ações ambientais, é fundamental para expandir a visão centralizada no ser-humano e em suas atividades antrópicas, possibilitando o resgate cultural do simbolismo da natureza, da água, de seus elementos e das suas diversas relações (DICTORO; HANAI, 2017).

Martínez Gil (2007) defende que uma nova cultura da água deve se basear na inclusão dos valores simbólicos, sentimentais, culturais e de memórias que os seres humanos possuem com a água e os rios. Portanto, ao olhar, sentir, ouvir ou até mesmo apreciar as águas, deve-se mirar uma obra de arte, como um símbolo histórico, cultural e ambiental, além do simples desejo e ganância de sua exploração e seu uso (MARTíNEZ GIL, 2007). 
Desse modo, com a inclusão de valores simbólicos, sentimentais e culturais, as pessoas podem vivenciar, sentir, apreciar e respeitar a natureza e seus elementos como símbolos culturais e históricos, muito além do simples desejo de uso e exploração. Há muitas comunidades nas quais se ouvem histórias de que antigamente, a relação com os recursos naturais era diferente. Resgatar essas histórias, documentá-las e divulgá-las pode se tornar um grande aliado na defesa das causas ambientais e propiciar um olhar mais respeitoso e harmônico para com a natureza.

\section{Diretriz de ação 5 - Utilização de imagens provocativas e de boa qualidade visual}

A utilização de imagens é um recurso que tem a capacidade de estimular a curiosidade e diferentes leituras nas pessoas, podendo provocar a necessidade de compreender melhor o que está sendo exibido, e, assim, despertar novos conhecimentos, comportamentos e outros valores importantes que podem ser trabalhados em atividades e ações de comunicação e Educação Ambiental.

Schultz et al. (2018) ressaltam a importância do uso de imagens que possam provocar emoções e envolver as pessoas em práticas pró-ambientais, tornando-se uma tática importante no campo da comunicação ambiental. Segundo Godfrey e Feng (2017), comunicar-se por meio de apelos emocionais fornece um método eficaz de influência sobre o comportamento, explorando respostas afetivas e efeitos mais poderosos do que a simples provisão de informações.

Para que as imagens utilizadas na comunicação ambiental sejam mais eficazes para transmitir e explorar as informações, algumas características são importantes, tais como: ter a capacidade de criar conexões emocionais; serem aderentes ao tema; possuir relevância pessoal e local; serem provocativas e reflexivas; possuir boa qualidade visual.

Os autores Godfrey e Feng (2017) destacam que a comunicação ambiental deve desenvolver campanhas significativas e relevantes para as pessoas, abordando aspectos de seu interesse local a fim de estimular 0 desenvolvimento de comportamentos pró-ambientais.

A representação de conteúdos locais e familiares para o público das atividades geram maior relevância e engajamento ambiental para as pessoas, pois, quando se identificam com o local que conhecem, se relacionam pessoalmente com as imagens utilizadas, o que pode favorecer e possibilitar ações e comportamentos pró-ambientais. As imagens são ferramentas excelentes que irão contribuir para que ocorra um maior engajamento em determinada ação e almejar a possibilidade de comportamentos próambientais. 


\section{Diretriz de ação 6 - Experiências de contato com a natureza e aprendizagem na natureza}

Valorizam-se as experiências de contatos diretos com a natureza e o meio ambiente. Essa abordagem pode facilitar e contribuir para o aprendizado das pessoas, criando uma relação entre ser humano e natureza. Gérin-Lajoie et al. (2018) destacam que aprender ciência com a experiência de campo, em um ambiente externo, contribui para o aprendizado e faz uma grande diferença na forma como as pessoas percebem e comprometem-se com o ambiente.

A aprendizagem ao ar livre ou em contato com a natureza pode desenvolver experiências que integram os conhecimentos técnicos e científicos com os conhecimentos práticos, resultando em atitudes e comportamentos próambientais de cuidado e valorização da natureza. Essa abordagem ajuda a despertar um sentimento de pertencimento e compreensão do meio ambiente, subsidiando uma visão sistêmica da natureza e de suas inter-relações.

Assim, Golob (2011) reforça que a aprendizagem ao ar livre possibilita desenvolver oportunidades de conhecimentos e experiências obtidas a partir do ambiente, de modo a integrar com os conhecimentos aprendidos dentro da sala de aula, podendo resultar em atitudes e comportamentos benéficos em relação ao meio ambiente.

Ao pensar em uma comunidade em que estejam sendo desenvolvidos projetos de Educação Ambiental, é importante propor esse contato para todas as idades, podendo então construir pontos com escolas, permitindo aos jovens desse local a possibilidade de se sentirem parte desse ambiente e se familiarizem com a importância da preservação e da conservação ambiental.

Outro fator importante está relacionado ao aprofundamento e ao envolvimento das pessoas nos temas ambientais, pois as experiências e contatos vividos na prática podem auxiliar no aprendizado de diversos temas e no sentido de cuidado e respeito com a natureza.

\section{Diretriz de ação 7 - Retratar problemas locais e ressaltar a cultura local}

A retratação de problemas locais irá facilitar as pessoas para enxergarem e interpretarem a realidade onde estão inseridas. Isso poderá auxiliar para que aumentem o entendimento e a compreensão das diferentes ações comportamentais que se pode ter com o meio ambiente.

Se sentir parte daquele local poderá despertar um desejo de cuidado e almejar comportamentos pró-ambientais, além de envolver as pessoas em atividades que conectam conhecimentos científicos com o saber e a cultura local. Dessa forma, possibilita-se dar sentido aos aspectos simbólicos e afetivos para aquele lugar, criando relações benéficas com o meio ambiente local, além de valorizar a cultura de determinadas regiões.

Gao et al. (2018) destacam que a conscientização pública sobre as questões da água, o senso de responsabilidade e as atitudes, além do apego 
ao lugar, são importantes fatores que influenciam as práticas e as ações individuais pró-ambientais. Os autores também reforçam que possuir um senso de responsabilidade em relação ao rio é um ponto positivo para um comportamento de proteção aos recursos hídricos. Assim, um aumento do envolvimento público em atividades ambientais também poderá ocasionar um aumento na conscientização das questões locais de qualidade da água e influenciar na disposição para proteger os recursos hídricos (GAO et al., 2018).

Nesse ponto também é importante olhar para a própria comunidade e observar se não ocorrem ações por parte da própria população voltada para Educação Ambiental. Caso ocorra, é uma oportunidade incrível de mesclar os saberes e de entender a fundo a realidade, a cultura, os problemas e as potencialidades do local.

Além disso, atividades que têm uma maior probabilidade de sucesso para promover mudanças em busca de um comportamento pró-ambiental incorporam diversas formas de conhecimento, além do técnico e científico, mas também o conhecimento subjetivo e local. Para isso, Hsu et al. (2018), a fim de despertar uma consciência ecológica e um comportamento pró-ambiental, defendem que é fundamental as pessoas terem experiências diretas e contato diário com a natureza e os elementos naturais, aumentando suas percepções e compreensões do meio ambiente.

\section{Diretriz de ação 8 - Estimular e desenvolver o aspecto coletivo}

O pensar coletivo e o compartilhar devem estar presentes na identidade das pessoas, e é justamente isso que deve e pode ser estimulado e desenvolvido nas ações de comunicação ambiental e Educação Ambiental em bacias hidrográficas, ou seja, uma visão coletivista e transformadora.

A sociedade coletivista enfatiza vários aspectos importantes para uma melhor convivência e bem-estar: a lealdade ao grupo (enquanto o grupo se preocupa com o bem-estar individual de todos); dependência emocional; menor privacidade pessoal; a crença de que as decisões tomadas em grupo são superiores às decisões individuais; interdependência; e ainda a compreensão e preocupação com as necessidades e interesses dos outros (DARWISH; HUBER, 2003).

Dessa forma, a sociedade coletivista irá ajudar a desenvolver novos sentidos e novas relações entre as pessoas e também das pessoas com o meio ambiente, favorecendo o surgimento de ações e comportamentos próambientais, desejando chegar a um bem-estar social coletivo, ou seja, para todas as pessoas.

Além do aspecto coletivo, é preciso também entender que cada pessoa tem sua visão, sua percepção e sua história de vida, deve-se buscar a construção de uma comunidade unida e democrática, mas sempre levando em conta que isso envolve muito esforço, muita dedicação e passa por escutar e refletir com todos. 


\section{Diretriz de ação 9 - Desenvolver e criar conexões emocionais e gerar comportamentos pró-ambientais}

Todas as diretrizes anteriores ajudam a desenvolver e criar conexões emocionais com a natureza e com seus elementos naturais. Com isso, almejase promover escolhas mais sustentáveis e benéficas ao meio ambiente, seja por meio de atividades e ações planejadas ou por meio de atitudes individuais e coletivas voltadas para um comportamento pró-ambiental.

Para isso, uma comunicação ambiental estratégica e transformadora aliada aos aspectos da Educação Ambiental emancipatória, transformadora e/ou crítica devem ser planejadas e executadas. Liang et al. (2018) ressaltam a importância de uma comunicação ambiental estratégica, que visa melhorar a eficácia de campanhas ambientais, promovendo atitudes e comportamentos pró-ambientais com o objetivo de garantir e preservar o bem-estar das sociedades e dos sistemas naturais.

Além disso, incorporar os diversos tipos de conhecimentos, conteúdos informativos adequados, linguagem simples, maior mobilização e participação das pessoas, retratar valores simbólicos, culturais e sentimentais, retratar problemas locais, estimular e desenvolver o aspecto coletivo, auxiliam no desenvolvimento e criação de conexões emocionais das pessoas com o meio ambiente, podendo resultar em despertar novos sentidos para as pessoas, resgatando valores culturais e possibilitando a geração de comportamentos pró-ambientais.

Uma comunidade que se envolve na construção de um local melhor, mais respeitoso e harmônico é uma comunidade que passa a criar conexões emocionais muito fortes com o local. Com isso, mais ações podem se espalhar e mais pessoas poderão ter essa percepção de uma relação, interação e comportamento pró-ambiental.

Por fim, ressalta-se que o formato em que as informações são apresentadas pode interferir positivamente ou negativamente nas ações e atividades realizadas. Com isso, o uso de uma linguagem adequada, coerente, não violenta e direcionada ao diálogo pode viabilizar uma maior interação com as pessoas, de maneiras mais respeitosa, democrática e solidária, e ainda motivar essas pessoas a promoverem esses valores na sociedade.

\section{Conclusões}

O atual modo de vida moderno vem se tornando cada vez mais exigente, intensificado por uma cosmovisão antropocêntrica, que vem alterando em ritmo cada vez maior as interações das pessoas com o meio ambiente. Nota-se que a sociedade moderna está cada vez mais desapegada de valores simbólicos, culturais e sentimentais com a natureza. Dessa forma, o meio ambiente tem sido frequentemente degradado pelos seres humanos, e é por isso que as ações individuais e coletivas das pessoas são fatores importantes na busca por novas formas de interação com a natureza.

revista brasileira educação ambiental 
Dentre os atuais problemas socioambientais, encontra-se 0 distanciamento entre os seres humanos e a natureza. Esse distanciamento pode ter sido gerado por diversos fatores como: a racionalidade; a apropriação da natureza; utilização exagerada dos recursos ambientais; e a degradação ambiental. Com isso, a relação humana com a natureza e seus elementos vem sendo suprimida e relacionada cada vez mais com o sentido da apropriação e da exploração. Considera-se que devem ser resgatados a subjetividade e o pensamento integrado do ser humano com a natureza, ressaltando valores de admiração, contemplação, cuidado, integração, simbólicos e culturais com a natureza e seus elementos. Esses valores são importantes para que se consiga alterar o rumo dos problemas socioambientais que vêm ocorrendo no mundo.

Assim, uma das formas de compreender e integrar os seres humanos com a natureza é por meio de uma Educação Ambiental e comunicação ambiental transformadora, reconectando e ressaltando valores simbólicos e culturais a fim de expandir a visão da relação ser humano e natureza. A Educação Ambiental aborda diferentes ações, atitudes e comportamentos, reconhecendo que muitas vezes essas ações são movidas pelas emoções, contatos e experiências que se tem com o meio ambiente, por isso, a reconexão entre ser humano e natureza poderá subsidiar uma mudança positiva rumo a comportamentos pró-ambientais. Ainda mais, a Educação Ambiental também pode auxiliar na construção de uma visão crítica, fortificando a necessidade de práticas positivas para enfrentar os problemas socioambientais, agindo com ética e justiça ambiental.

Para que tudo isso seja efetivo e alcance grande parte da sociedade, deve-se ter uma comunicação ambiental adequada, seguindo princípios e diretrizes que reforçam o planejamento das ações vinculadas com a Educação Ambiental. A comunicação ambiental deve informar e incentivar novas práticas de comportamentos pró-ambientais, promovendo escolhas mais sustentáveis e benéficas ao meio ambiente.

\section{Agradecimentos}

A Coordenação de Aperfeiçoamento de Pessoal de Nível Superior (CAPES) pelo apoio concedido ao financiamento da pesquisa (Código de Financiamento 001) que deu origem a esse artigo científico, à Universidade Federal de São Carlos, por tornar possível o doutoramento do primeiro autor.

\section{Referências}

ABERS, R.; JORGE, K.D. Descentralização da gestão da água: porque os comitês de bacia estão sendo criados. Ambiente \& Sociedade, São Paulo, v.8, n.2, p. 99 - 124, 2005.

BACCI, D.L.C.; PATACA, E.M. Educação para a água. Estudos avançados, São Paulo, v. 22, n. 63, p. 211 - 226, 2008. 
BARBOSA, F.D. Comitês de Bacias Hidrográficas, representação e participação: desafios e possibilidades à gestão da água e dos recursos hídricos no Brasil. 2019. Tese (Doutorado em Ciências Ambientais) - Centro de Ciências Biológicas e da Saúde, Universidade Federal de São Carlos, São Carlos - SP.

BARROS, A.J.S.; LEHFELD, N.A.S. Fundamentos de metodologia: um guia para a Iniciação Científica. 2 Ed. São Paulo: Makron Books, 2000.

CARDOSO, M.L.M. Desafios e potencialidades dos comitês de bacias hidrográficas. Ciência e Cultura, Campinas, v. 55, p. 40-41, 2003.

COHEN, M.P.; SAENZ, I.Z. Perspectivas ambientales sobre la contaminación y la recuperación del río Magdalena en la ciudad de México. Revista internacional de contaminación ambiental, Coyoacán, v. 33, n. 3, p. 377 391, 2017.

DARWISH, A.F.E.; HUBER, G.L. Individualism vs Collectivism in different cultures: a cross-cultural study. Intercultural Education, v. 14, n. 1, p. 47-56, 2003.

DICTORO, V.P.; FIGUEIREDO, R.A.; CASSIMIRO, M.O.; GONÇALVES, J.C. A relação ser humano e natureza a partir da visão de alguns pensadores históricos. Revista Brasileira de Educação Ambiental, São Paulo, v. 14, n. 4, p. $159-169,2019$.

DICTORO, V.P.; HANAI, F.Y. Contribuições para a conservação da água: pesquisa com membros de Comitês de Bacias Hidrográficas. Caderno de Geografia, Belo Horizonte, v. 27, n. 49, p. 227-246, 2017.

FERREIRA, F.N.; RIBEIRO, H.M.C.; BELTRÃO, N.E.S.; PONTES, A.N.; LOPES, S.R.M. Gestão de recursos hídricos na Amazônia: um panorama da participação da sociedade civil nos espaços deliberativos. Holos, Natal, v. 8, p. $336-351,2017$.

GAO, Y.; CHURCH, S. P.; PEEL, S.; PROKOPY, L. S. Public perception towards river and water conservation practices: Opportunities for implementing urban stormwater management practices. Journal of Environmental Management, v. 223, p. $478-488,2018$.

GÉRIN-LAJOIE, J.; HERRMANN, T.M.; MACMILLAN, G.A. ; HÉBERT-HOULE, E.; MONFETTE, M. IMALIRIJIIT: A Community-Based Environmental Monitoring Program in the George River Watershed, Nunavik,Canada. ÉCOSCIENCE, v. 25, n. 4, p. $381-399,2018$.

GIL, A.C. Métodos e técnicas de pesquisa social. $6^{\underline{a}}$ ed. São Paulo: Editora Atlas, 2012.

GODFREY, M.; FENG, P. Communicating sustainability: Student perceptions of a behavior change campaign. International Journal of Sustainability in Higher Education, v. 18, n. 1, p. 2 - 22, 2017. 
GOLOB, N. Learning Science through Outdoor Learning. The New Education Review, v. 25, n. 3, p. $221-234,2011$.

HSU, W.-C.; TSENG, C.-M.; KANG, S.-C. Using exaggerated feedback in a virtual reality environment to enhance behavior intention of water conservation. Educational Technology \& Society, v. 21, n. 4, p. 187 - 203, 2018.

JUNIOR, S.P.R. et al. Governança colaborativa aplicada à gestão de conflitos socioambientais na despoluição de córregos na cidade de São Paulo. Revista Brasileira de Gestão e Desenvolvimento Regional, Taubaté, v. 11, n. 1, p. $113-134,2015$.

LIANG, Y. J.; KEE, K.F.; HENDERSON, L.K. Towards an integrated model of strategic environmental communication: advancing theories of reactance and planned behavior in a water conservation context. Journal of Applied Communication Research, v. 46, n. 2, p. 135 -154, 2018.

LOUREIRO, C.F.B. Educação Ambiental transformadora. In: LAYRARGUES, P. P. (coord.). Identidades da Educação Ambiental Brasileira. Brasília: MMA, 2004, p. 65-84.

MARTíNEZ GIL, F.J. Los problemas del agua en España: análisis de una realidad. Enseñanza de las Ciencias de la Tierra, v. 15, n. 3, p. $228-239$, 2007.

OLIVEIRA, H.T. Potencialidades do uso educativo do conceito de bacia hidrográfica em programas de Educação Ambiental. In: SCHIAVETTI, A.; CAMARGO, A. F. M. (Orgs.). Conceitos de bacias hidrográficas: teorias e aplicações. Ilhéus: Editus, 2002. p. 125-138.

PERKINS, P.E. Public participation in watershed management: International practices for inclusiveness. Physics and Chemistry of the Earth, v. 36, p. 204 $-212,2011$.

PINTO, B.C.T.; BORGES, J.L. C. Uma atividade de Educação Ambiental em espaço não formal: potencialidades do uso de bacias hidrográficas. Tempos e espaços em educação, São Cristóvão, v. 8, n. 16, p. 109 - 124, 2015.

SCHULTZ, T.; FIELDING, K.; NEWTON, F. Images that engage people with sustainable urban water management. Science Communication, v. 40, n. 2, p. 199 - 227, 2018.

TEIXEIRA, A.C. Educação Ambiental: caminho para a sustentabilidade. Revista Brasileira de Educação Ambiental, v. 2, n. 1, p. 23-31, 2007.

TUNDISI, J.G. Governança da água. Revista da UFMG, Belo Horizonte, v. 20, n. 2, p. $222-235,2013$.

VILAÇA, M. F. et al. Bacia hidrográfica como unidade de planejamento e gestão: o estudo de caso do ribeirão Conquista no município de Itaguara - MG. Anais do XIII Simpósio Brasileiro de Geografia Física Aplicada. Viçosa-MG, 2009. Disponível em: < http://www.geo.ufv.br/simposio/simposio/trabalhos/trabalhos completos/eixo3/0 70.pdf>. Acesso em 20 Mar 2021. 